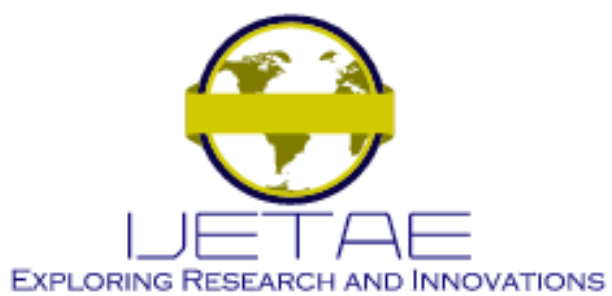

International Journal of Emerging Technology and Advanced Engineering

Website: www.ijetae.com (E-ISSN 2250-2459, Scopus Indexed, ISO 9001:2008 Certified Journal, Volume 11, Issue 10, October 2021)

Manuscript Received: 01 September 2021, Received in Revised form: 04 October 2021, Accepted: 14 October 2021

DOI: 10.46338/ijetae1021_15

\title{
Fuzzy based Decision Support Model for Deciding the Students' Academic Performance
}

\author{
Ditdit Nugeraha Utama ${ }^{1}$, Deddy Kurniawan ${ }^{2}$ \\ ${ }^{1,2}$ Computer Science Department, BINUS Graduate Program - Master of Computer Science, Bina Nusantara University, \\ Jakarta, Indonesia 11480
}

\begin{abstract}
In the education domain, especially in higher education, a standard of performance assessment is determined by the grade point average (GPA). In its use in the evaluation process, GPA assessment standards have some shortcomings, such as focusing only on the improvement of the GPA value regardless of other factors that can affect an evaluation result, so that the GPA standard cannot be used as one and only one basic reference in determining the results of performance evaluation ideally. The study is a completed version of the previous one. The purpose of this study is to construct a decision support model (DSM) that can conduct performance assessment by considering various parameters that are considered to affect the academic performance results of students. The model was constructed by using three methods: fuzzy logic of Sugeno, conventional, and mathematical. This study uses quantitative data analysis because the data used is real data in the form of personal data and academic value data of students in the field. The predetermined methods were implemented in this study to calculate the academic performance value of students by considering various other parameters outside the GPA parameters. So that the assessment results will be more ideal and can strengthen the standard of GPA assessment in conducting the process of evaluating student performance. Also, finally, the verification and validation values of the model are represented.
\end{abstract}

Keywords - assessing, student's academic performance, fuzzy logic, fuzzy inference model, sugeno.

\section{INTRODUCTION}

Conducting performance evaluation is a very important thing to do in education domain [1]. At universities, the performance evaluation process is carried out by stakeholders as related academics, the evaluation is carried out with the aim of analyzing the development of student performance in going through the learning period for a certain time. The performance evaluation process is very dependent on various assessment results that have been made as a reference standard in conducting evaluations.
In general, the evaluation process is based on the grade point average (GPA) of students, which is a form of grouping the GPA scores based on the range of a predetermined group, such as poor, good, very good, and excellent [2].

Assessment is a big part of an evaluation process carried out on the performance of the GPA. Academic performance assessment is one of the effective solutions to detect student failure problems by analyzing their data warehouse so that it can help to provide important information in the process of assessing their academic performance. In practice, the complicated work of evaluating performance is carried out based solely on the classical assessment method using the standard GPA assessment. Where the classical assessment method is a form of presenting an assessment based on a comparison of student performance results with the standard GPA value category that has been set [3]. This is a drawback than the classical assessment method (standard GPA assessment) when used as a basis for evaluating student performance. So that in the evaluation process it would be very unfair to only evaluate and produce a decision by considering only one factor (GPA), without looking at the factors that affect the achievement of the GPA score as the current standard of assessment [4].

Talking about research related to the important issue of academic performance appraisal, researchers have made various efforts to be able to contribute to this important issue of education. In research that has been successfully completed [5], states that an evaluation based on the classical performance appraisal method embedded in a certain numerical notation cannot state a statement as true or false, or good and bad. They proposed a model based on the fuzzy analytic hierarchy process (FAHP), a model used in evaluating student performance in student projects they were working on by considering most of the forgotten factors in the classical performance appraisal method. 


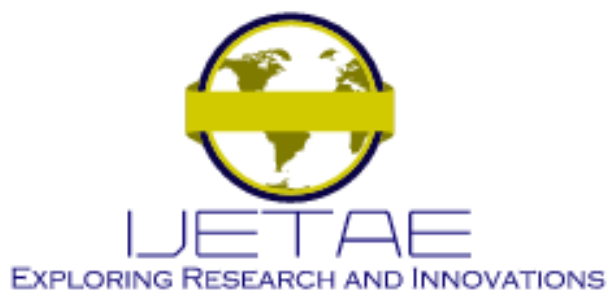

International Journal of Emerging Technology and Advanced Engineering

Website: www.ijetae.com (E-ISSN 2250-2459, Scopus Indexed, ISO 9001:2008 Certified Journal, Volume 11, Issue 10, October 2021)

Furthermore, [6] stated that most higher education institutions use GPA scores to evaluate student performance. However, this is "the only theory of achievement" that cannot be used for performance evaluation over a certain period of time. A comprehensive model in performance evaluation is proposed to improve the classical evaluation method. The proposed model was developed by prioritizing the comprehensive quality of students based on the AHP.

Assessment of student academic performance conducted at one university specified in one faculty of teacher training and education (FTTE) focuses more on indications of GPA achievement. Policy makers tend to focus more on increasing the value of the GPA. That makes various policies focused on increasing the GPA over a certain period of time. Instead of increasing academic achievement through the GPA indicator, it does not touch the supporting factors for achieving the GPA value from various factors, including family, social, cultural, economic, educational environment, and technology. The classical assessment method in supporting the academic evaluation process carried out by FTTE does not comb through the factors that achieve GPA.

The stages of assessing the academic performance of students in higher education are very important for every educational institution, because the quality of education of an educational institution will have an impact on the accreditation assessment for FTTE in maintaining and continuing to improve the quality of graduations produced every year. By taking quick steps through the implementation of strategies by identifying and classifying students based on their academic performance they are deemed able to provide input in the form of knowledge of academic performance achievements. The results of each individual student will be used as evaluation material to determine the right strategy to improve the achievement of academic performance for each individual with poor academic performance. From some of the background points of the research above, it is important that research on academic performance appraisal is studied in depth.

Assessment of student's academic performance is carried out by considering various factors / parameters related to the issue of academic performance assessment, so that an assessment method will be obtained that can participate in supporting and strengthening the classical assessment method. This research is a completed version of [7].
It was conducted by combining two types of research sample data, namely profile data and student academic record data for the 2019-2020 academic year with a total dataset of 100 student data samples. Profile data stores large information that has not been extracted and is valuable to identify to find out various factors outside of academics that can affect the achievement of GPA scores. This research is expected to provide two contributions that the author gives in the implementation of this research, namely, academic contributions and practical contributions. The academic contribution of the research produced is that the DSM model can be a reference for research in the field of education and an analytical method in assessing student academic performance. The practical contribution of this research is that the DSM model can be used as a reference and reference for universities in assessing student performance.

Also, as mentioned before, the paper is a finished edition of [7]. It talks about a DSM for determining a student's academic performance by using fuzzy logic conception. The background of the paper followed by theoretical view, related works, research methodology, result and discussion, and conclusion and further works.

\section{THEORETICAL VIEW}

\section{A. Academic Performance}

Academic performance (AP) is an educational outcome, the extent to which students, teachers or schools have achieved their goals in school education [8]. Meanwhile, another definition of AP is a process to achieve knowledge and is evaluated based on the value given by the teacher. In school education, AP is the achievement of educational goals by students, teachers or schools within a certain period of time and is assessed through regular evaluations and or examinations and the objectives may differ between students and schools [8]. Academic performance is a process that occurs in the learning process within a certain period of time which aims to achieve an educational goal, namely an academic achievement which is then evaluated based on the value given by the teacher or through a test process or regular exam. Academic performance provides an overview of the student's ability to understand and study a given learning material which then becomes a provision for obtaining more complex knowledge [7]. 


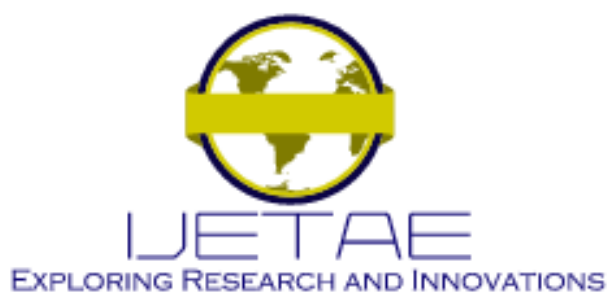

International Journal of Emerging Technology and Advanced Engineering

Website: www.ijetae.com (E-ISSN 2250-2459, Scopus Indexed, ISO 9001:2008 Certified Journal, Volume 11, Issue 10, October 2021)

\section{B. Decision Support Model}

The decision-making model was first introduced in the early 1970s by Micheal S. Scott Morton with the term management decision system [9]. The decision-making model or decision support model (DSM) has a concept that is characterized by a computer-based interactive system that helps to make decision by utilizing data and methods to solve unstructured problems. The DSM aims to support all stages of decision making, from identifying problems, selecting data, and choosing an approach that will be used in the decision-making process, to evaluating alternative choices. The fundamental components that must exist in the decision-making model concept are model components, data components, and user interfaces [10] and [11].

Decision-making model is one way to solve problems in any business process. In principle, making a decision is based on a problem in an effort to achieve a certain goal [12]. DSM is not a tool for making decisions, but a model developed by equipping them with information from data that has been processed relevantly and needed to make decisions about a problem more quickly and accurately in a company or organization. according to [13]. DSM can solve problems from semi-structured problems explicitly. In another discussion, according to decision-making models can solve some problems mathematically where the model is built with the best decision in providing an objective solution to answer the existing problems.

\section{Fuzzy Logic}

The idea of a fuzzy set was born with mathematics and system theory introduced by [14], fuzzy sets have the ability to overcome inaccuracies and uncertainties through an approach using linguistic terms and membership levels. Fuzzy logic (FL) is a branch of logic that is specifically designed to represent human knowledge and reasoning in a way that allows it to be processed by a computer [4]. FL has a high chance of influencing the calculated model to accept human linguistic factors. The FL technique has implications that contain all changes in linguistic control procedures depending on the master's learning into the programmed control system. The change procedure is called fuzzification-defuzzification in producing the output. This fuzzification involves a domain transformation where sharp inputs are measured and passed to the machine for processing before being converted into fuzzy outputs. The defuzzification process produces measurable results in sharp logic, given fuzzy sets and appropriate membership degrees. It is operated to convert crisp input to crisp output which is ready to operate into the model.
In real life, FL is widely used to solve problems in the case of expert systems and real-time systems that are required to be able to adapt in an imperfect environment with conditions that vary widely, change easily, are unclear or fuzzy. The term fuzzy can be used to represent an evaluation of academic performance that involves measuring abilities, and skills. The fuzzy hierarchical approach is used to evaluate student achievement and is further classified into certain class groups. FL based approach proposed in research [15] to evaluate student performance at school or college by providing soft and appropriate results for students.

\section{RELATED WORKS}

New models to support goals in the academic performance appraisal process are still being investigated and scientifically researched. One of them is a study related to DSM. Research has been carried out by a number of researchers through DSM as the main issue. There have been several studies of DSM proposing various methods used for the assessment of AP.

Performance-based academic decision-support system (PADSS) is used to make decisions on academic performance outcomes [16]. PADSS was built to meet the need to evaluate performance results using the GPA parameter as the main parameter. The data used by PADSS are case studies specific, but the PADSS framework is still general in nature and can be used to evaluate APs.

In other studies, [2] conducted AP evaluation by comparing three data mining classification methods; Decision Tree, Naïve Bayes and K-Nearest Neighbor. AP evaluation was carried out by involving several parameters such as gender, community, and family size. The results of the evaluation are in the form of predictions of academic performance from each method that is carried out and succeeded in providing the desired prediction results with a high level of accuracy.

Research done by [17] in the field of educational data mining (EDM) by creating predictive models for AP that are applied to specific datasets. The model is built using three popular data mining classification methods Naïve Bayes, Neural Network and decision tree and is run by using several input parameters related to AP results such as area of origin, type of transportation, distance traveled, motivation, father's education, and mother's education. The results of the model development show good results in making AP predictions and can run according to the average model accuracy of $80 \%$. 


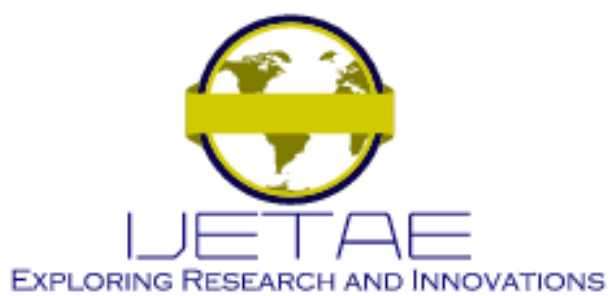

International Journal of Emerging Technology and Advanced Engineering

Website: www.ijetae.com (E-ISSN 2250-2459, Scopus Indexed, ISO 9001:2008 Certified Journal, Volume 11, Issue 10, October 2021)

In other EDM fields [18] using the support vector machine (SVM) in the prediction model built. The model uses new parameters in making AP predictions such as, family income, scholarships, travel and family status. Prediction models built with SVM can run well but still give low accuracy results. In addition, research [19] in the EDM field, it is done by comparing 9 Naïve Bayes algorithms, decision tree (J48), random forest, random tree, REPTree, JRip, OneR, simple logistic, and Zero R on the built AP prediction model. The model is built using 33 input parameters of the model including new parameters in AP predictions such as place of residence and travel time.

Furthermore, it is still related to the prediction of AP being developed by building a hybrid model using the J48 and ID3 methods. The hybrid model was built to provide information on bad AP warnings by carrying out specific case studies. [20] adding social media parameters as new parameters of the parameters that have an influence on the AP prediction results.

Based on the literature review above, research related to AP assessment has been carried out by other researchers by proposing various approach methods they use, the EDM approach using data mining algorithms is a research trend related to AP that is specifically applied to predict and classify data. In addition to research using the EDM approach, research with a decision support system approach has also been previously investigated using the PADSS model which is used to make decisions in AP evaluation. There are various parameters that have been proposed with the main objective of evaluating AP such as, GPA [16], gender, community, family size [2], place of origin, transportation, mileage, motivation, father's education, mother's education [17], family income, scholarship, traveling, family status [18], residence, travel time [19], and social media [20].

The field of DSM research is an approach to the problem by taking into account scientifically and mathematically with the aim of producing an ideal decision by involving various factors that are considered to have an effect on the occurrence of a problem. The FL method has the advantage of mapping an input from a problem into a fuzzy logic to be able to produce an output in the form of a decision approach as the final result of the model. Therefore, the application of FL provides the advantage of a new, efficient form of assessment that can be applied by offering various forms of assessment that can be adapted based on needs and problems to assist in the in-depth evaluation process.
In the end, the research done by determining what methods will be used to be applied in building the model. Some of the methods that will be used are the FL Sugeno method, conventional, and the mathematical method which have never been applied in previous studies. The rationale for choosing the FL method is that the basic concept form of the FL method can make a decision on a problem based on the concept of a fuzzy rule base that maps out all the possibilities that can occur in a problem. This is similar to the form of human reasoning by considering the various parameters involved, so the FL method will be very helpful in solving unstructured forms of problems such as conducting AP assessments.

Furthermore, the selection of the FL method technique is the Sugeno technique. The Sugeno technique was chosen because it has the ability to be combined with simple mathematical calculations to produce decisions, where in performing calculations to produce crisp output values, FL Sugeno centroid method (average) in the defuzzification process (de-fuzzy) which can increase the accuracy. from the output value with the output from FL Sugeno can be a mathematical function or constant [21]. This is a feature of the Sugeno technique that is not shared by other techniques from other FL methods that will be utilized in building the model. In addition, the selection of the FL Sugeno method is also based on the input data type. The parameters to be used are numeric and nominal data types. The FL Sugeno method will be operated in handling input in the form of numeric data types.

As for the nominal data type, the conventional method will be used by changing the format of the nominal data type into data with a numeric type to facilitate the calculation process. In the final assessment process of the model, mathematical modeling will be applied which describes the assessment process involving various parameters which are grouped into two parts which will be represented by symbols (ax) and (bx).

\section{RESEARCH METHODOLOGY}

\section{Research Framework}

The research framework describes how the research concept will be carried out in conducting research. The AP assessment process which is a research issue is carried out via constructing a DSM as a problem-solving solution to be applied to the FTTE at Mulawarman University, East Kalimantan. 


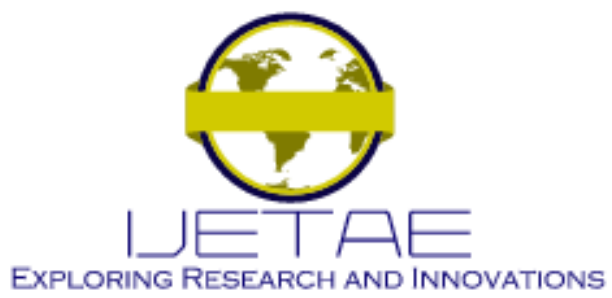

International Journal of Emerging Technology and Advanced Engineering

Website: www.ijetae.com (E-ISSN 2250-2459, Scopus Indexed, ISO 9001:2008 Certified Journal, Volume 11, Issue 10, October 2021)

The first thing to do is to identify the problems faced by FTTE, which is the largest faculty at Mulawarman University, East Kalimantan. Assessment of student academic performance conducted at the FTTE at Mulawarman University focuses more on indications of GPA achievement. Policy makers tend to focus more on increasing the value of the GPA. That makes various policies focused on increasing the GPA over a certain period of time. Instead of increasing academic achievement through the GPA indicator, it does not touch the supporting factors for achieving the GPA value from various factors, including family, social, cultural, economic, educational environment, and technology.

The classical assessment method in supporting the academic evaluation process carried out by FTTE does not comb through the factors that achieve GPA. The stages of the AP assessment of students in higher education are very important for every educational institution, because the quality of education of an educational institution will have an impact on the accreditation assessment for FTTE in maintaining and continuously improving the quality of graduations produced every year. By taking quick steps and implementing strategies by identifying and grouping students based on their academic performance they are deemed able to provide input in the form of knowledge of AP achievements produced by each individual student. This step is used as an evaluation material to determine the right strategy to improve the achievement of academic performance for each individual with poor academic performance. Therefore, this study conducted a literature study to strengthen the foundation regarding what concepts, methods, and parameters are used to build a decisionmaking model that aims to conduct AP assessment for students.

The developed model is named DSM-AP, built by identifying and weighting parameters to be used as input parameters in the model, while the model uses a combination of three methods, FL Sugeno, conventional, and mathematic model. The next step is to collect data for later analysis of data requirements related to the AP assessment including the data pre-processing process. The data from the analysis will eventually be used as a data source (dataset) that will be used in building the model.

\section{E. Research Stages}

The research stages are taken from [7]. The first step of the research begins with the process of reviewing real cases in terms of AP assessment supported by the results of reviewing several scientific manuscripts related to research issues. These two stages are carried out to enrich knowledge related to research issues regarding $\mathrm{AP}$ assessment. Next, define the parameters related to the assessment of AP based on the results of the literature study. Related research involving various parameters that are validated based on various references from previous studies to be used in conducting AP assessment. All parameters obtained are combined to be used in building the model with a total of 17 parameters. Then all parameters will be configured which includes; parameter grouping configuration and parameter weighting configuration. After the parameter preparation process has been successfully carried out, then data collection is carried out to be prepared as a dataset by going through the data pre-processing process.

The stages of building the model are carried out by weighting parameters as the initial configuration of the model, weighting aims to identify the magnitude of the influence of various parameters on the AP assessment. Furthermore, the FL Sugeno, conventional, and Mathematical methods were operated on the model. FL Sugeno is used to calculate the value of (ax) based on the input of fuzzy parameters. Conventional calculations are used to calculate the value of $(b x)$ based on the input of conventional parameters. With the results of the two methods, the mathematical method is used in the final calculation of the AP assessment based on the Sugeno and conventional FL calculations.

\section{RESUlt AND DisCUSSION}

\section{A. Selected Parameters}

This section describes the process and basis for selecting parameters to be used in building the model. The determination of the parameters used is based on references from previous studies that are closely related to the research topic. The parameters that have been proposed in previous studies were collected and combined in this study by depicting them through the Venn diagram in Figure 1 and the weight of parameters was taken from [7]. 


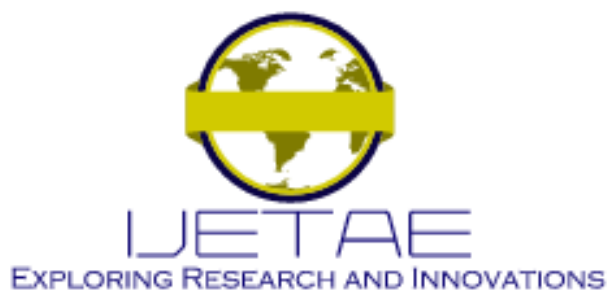

International Journal of Emerging Technology and Advanced Engineering

Website: www.ijetae.com (E-ISSN 2250-2459, Scopus Indexed, ISO 9001:2008 Certified Journal, Volume 11, Issue 10, October 2021)

\section{B. Dataset Resource}

The dataset that operated in the study was collected through two methods, namely: (1) distributing online questionnaires using Google Forms services to collect profile data from each student, (2) downloading the student academic data archives contained in the SIA at FTTE of Mulawarman University, East Kalimantan. The data collection carried out includes student data for the 2019/2020 academic year with the amount of data for academic performance assessment totaling 100 data, where the dataset used can represent a large population in the FTTE environment with various data variations for each input value used. as a test case on the model. The form in the form of the data format of the dataset that will be used is described in TABLE 1.

\section{Parameter Grouping}

In this subchapter, the parameter configuration is explained by grouping all the parameters used in the model. The configuration stage is based on the use of research data types in the form of numeric and nominal data; where based on the data type will also differentiate the method that will be operated on each parameter group. Parameter grouping is done by dividing the group into two groups of parameters, namely; fuzzy parameter group is represented by $a x$ to be operated on numeric data type and conventional parameter group is represented by $b x$ to be operated on nominal data type. In the parameter $b x$, further configuration is carried out by encoding the data including the attributes of each parameter. Attribute values in the form of nominal data are formatted into numeric data represented by the Boolean data type. An attribute value of 0 indicates the ideal condition of an input value, while an attribute value of 1 indicates a special condition that has an impact on performance appraisal.

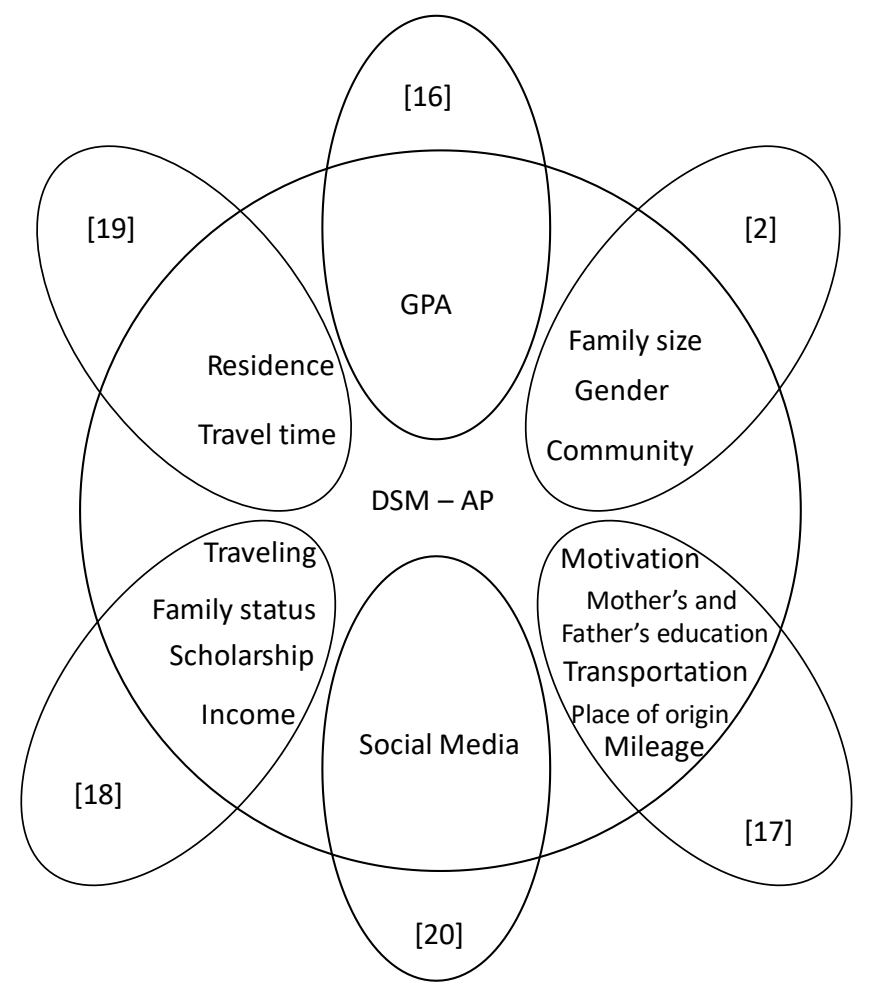

Figure 1. Diagram Venn of Selected Parameters

TABLE I

COllected Dataset

\begin{tabular}{|c|c|c|c|c|c|c|c|c|c|c|c|c|c|c|}
\hline No & P1 & P2 & P3 & P4 & P5 & P6 & P7 & $\ldots$ & P12 & P13 & P14 & P15 & P16 & P17 \\
\hline 1 & M & OT & 1 & DE & H & 1 & 1 & $\ldots$ & PB & Y & Y & 4 & 2 & 3,56 \\
\hline 2 & F & T & 3 & L & P & 3 & 2 & $\ldots$ & PR & N & Y & 4 & 4 & 2,41 \\
\hline$\ldots$ & $\ldots$ & $\ldots$ & $\ldots$ & $\ldots$ & $\ldots$ & $\ldots$ & $\ldots$ & $\ldots$ & $\ldots$ & $\ldots$ & $\ldots$ & $\ldots$ & $\ldots$ & $\ldots$ \\
\hline 99 & F & OT & 3 & L & P & 4 & 3 & $\ldots$ & PR & N & N & 6 & 2 & 3,57 \\
\hline 100 & M & OT & 3 & L & P & 4 & 3 & $\ldots$ & PR & N & N & 8 & 4 & 3,19 \\
\hline
\end{tabular}

\section{Variable Analysis}

In the world of engineering, influence diagram is a tool to represent in graphical form of a decision model that is used to assist model design, development and understanding of a system. In building the model the author uses influence diagrams to represent the graphical form of the model as shown in Figure 2. 


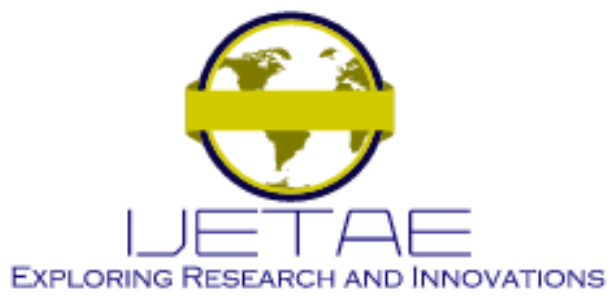

International Journal of Emerging Technology and Advanced Engineering

Website: www.ijetae.com (E-ISSN 2250-2459, Scopus Indexed, ISO 9001:2008 Certified Journal, Volume 11, Issue 10, October 2021)

Based on the influence diagram in Figure 2, it can be seen that the hexagonal symbol that shows the output of the research is to determine the decision in the form of the final assessment result (decision value) of the students' academic performance within a certain period of time. The output is the expected output of solving existing problems (decision indicators) of the model. In determining the output $(D V)$ results, it is carried out based on the AP assessment which is determined based on two main parameters that are input to the model, namely the fuzzy group $a x$ and the conventional group $b x$; Where the two main parameters are influenced by other parameters.

The $a x$ is influenced by nine parameters which include; GPA, trip length, travel distance, mother's education, father's education, family income, number of siblings, travel style, and social media. While the $b x$ is influenced by eight parameters which include; scholarship, of transportation type, family status, motivation, gender, origin area, community, and residence place. The model was built using a combination of 3 methods, namely FL Sugeno, conventional, and Mathematic models.

\section{E. Constructed Model}

This section describes the development of a model for AP assessment described in a high-level model configuration. The configuration of the model made is designed in accordance with the basic structure of the DSM. The configuration at the initial stage is done by determining what parameters will be used in building the DSM-AP model based on the results of the literature study.

Furthermore, the results of determining the parameters will be carried out in two configurations namely grouping and parameter weighting, the grouping configuration is carried out by forming two types of parameter groups namely $a x$ representing the parameters for the FL Sugeno method and $b x$ representing the parameters for the conventional method, where the grouping is based on the calculation method on the model and the type of data type as the model input value. The next configuration is weighting which is carried out in two stages, first to produce an estimated initial weight calculation of each parameter based on data in the field, carried out using the RapidMiner tool, then the results of the initial weight estimate are normalized to obtain the final weight value.

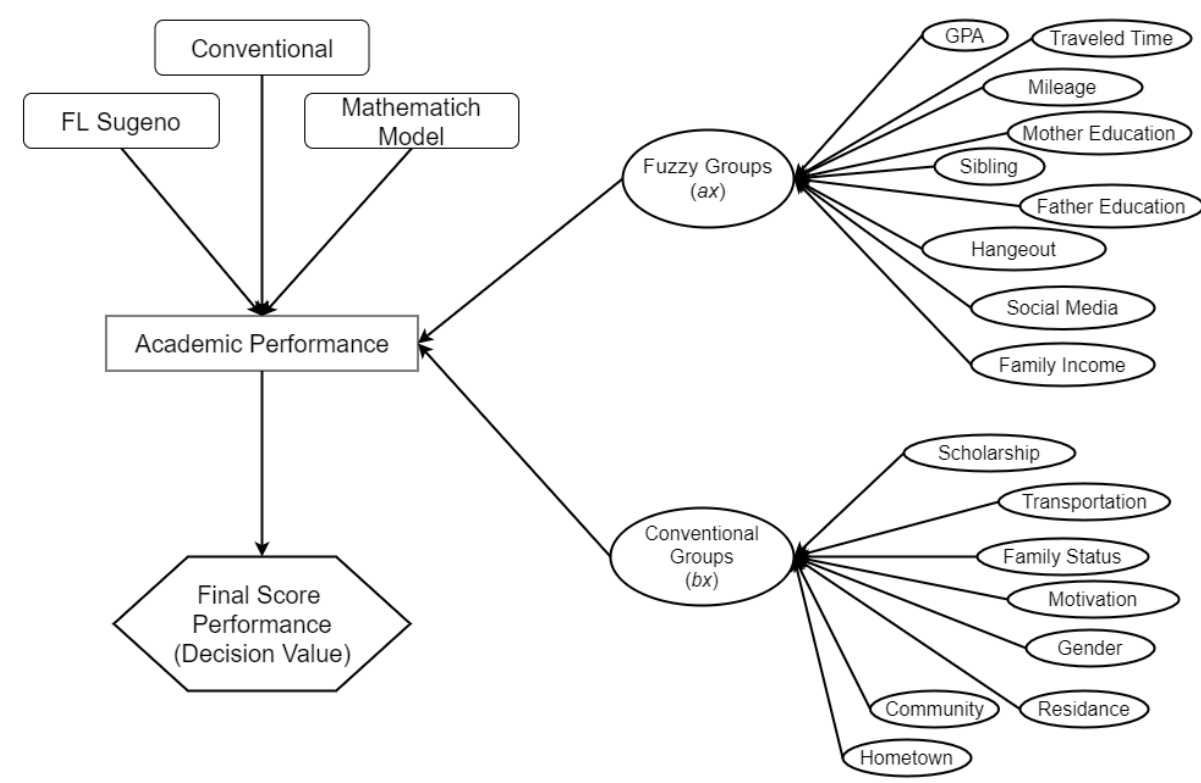

Figure 2. Influence Diagram of the Constructed DSM 


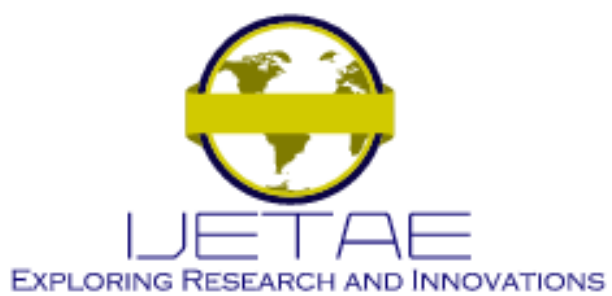

International Journal of Emerging Technology and Advanced Engineering

Website: www.ijetae.com (E-ISSN 2250-2459, Scopus Indexed, ISO 9001:2008 Certified Journal, Volume 11, Issue 10, October 2021)

The next configuration is done by determining the value in the parameter attribute $b x$, the results are shown in TABLE III. The next configuration is done by operating the conventional method, the final result of the conventional method shows the value of the influence of the parameters $b x$ on the results of the AP assessment. The conventional method is successfully operated, then the FL Sugeno method will be operated which includes the stages of the fuzzy concept (fuzzy-inference-de-fuzzy), the results of the FL method are obtained where the final result of the FL Sugeno method shows the value of the influence of the parameters $a x$ on the results of the AP assessment. Furthermore, the calculation to obtain the final value of the $\mathrm{AP}$ assessment is expressed in decision value $(D V)$ which is a form of mathematical modeling of the AP assessment in this study. And finally, the results of the AP assessment for each individual student are stated with a value range of 0-100.

\begin{tabular}{|l|}
\hline \multicolumn{1}{|c|}{ student } \\
\hline + gender : char \\
+ hometown : char \\
+ sibling: int \\
+ familyStatus : char \\
+ residence : char \\
+ fatherEducation : int \\
+ motherEducation: int \\
+ familylncome : int \\
+ motivation : char \\
+ mileage : int \\
+ traveledTime: int \\
+ transportation : char \\
+ scholarship : char \\
+ community : char \\
+ socialMedia : int \\
+ hengeOut : int \\
+ GPA: float
\end{tabular}

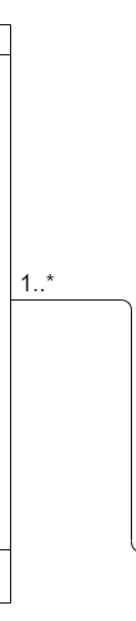

Figure 3. Class Diagram for the Constructed Model

\section{F. Model's Class Diagram}

Class diagram (CD) of model is constructed to show a set of classes, interfaces, and collaborations and the relationships that exist in them. The $\mathrm{CD}$ of the model is shown in Figure 3. In Figure 3, illustrates the CD used to build the model consisting of one type of class, namely student. The CD model can be read: one student has one performance value, where performance is obtained based on many FL values with FL values generated based on many membership functions and fuzzy rule bases.

\section{G. Model's Process Flow}

In carrying out the construction of the model that will be used in real terms in conducting the AP assessment. The initial stage is to prepare the parameters that used in building the model. The required parameters were collected through a literature study at the beginning of the study which resulted in as many as 17 parameters (taken from [7]), to then be used when building the model. The attribute value of each parameter is defined based on real facts in the field so that the model built can be closer to the truth value of the problem.
TABLE II

DATA SAMPLES

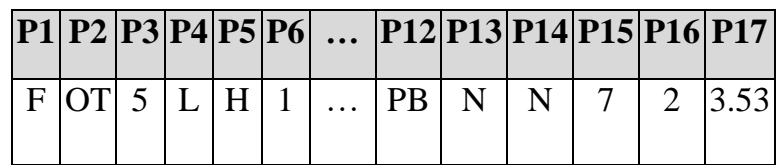

The sample data is processed by working on the input parameter bx first. The number of parameter values bx is 3 then multiplied by the weight value $\left(\sum \mathrm{WC}\right)$ of 0.1188 so that for the final result of the conventional method the value $\left(\sum(b x)\right)$ is 0.36 . The results of the conventional method are shown in TABLE III. Conventional calculation results for all datasets are shown in TABLE IV.

The second stage of the model calculation is carried out using the FL Sugeno method. The initial stage of the concept of the FL method begins with the fuzzy stage. The fuzzy stage is the process of mapping the crisp (numeric) value of the input model for the parameter member $a x$ into the fuzzy set and determining the value of the degree of truth. 


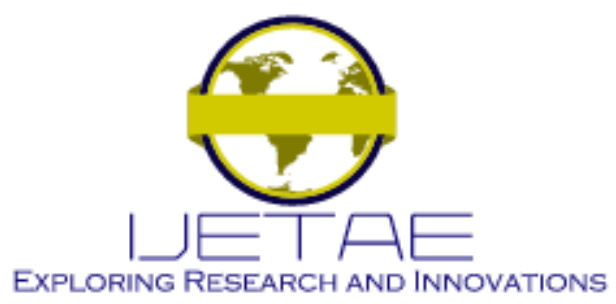

International Journal of Emerging Technology and Advanced Engineering

Website: www.ijetae.com (E-ISSN 2250-2459, Scopus Indexed, ISO 9001:2008 Certified Journal, Volume 11, Issue 10, October 2021)

MF and LV were defined in the early stages of the FL method and to be used as a calculation scale. The role of $\mathrm{LV}$ in the concept of the FL method is used to explain the condition level of each fuzzy parameter which is calculated academically. LV is then designed through MF in the form of a graph representing the degree of membership of each input parameter value that is in the interval between 0 and 1. The degree of membership of a variable $x$ is denoted by the symbol $x$. The rules use the membership value as a weighting factor to determine its effect when making inferences in drawing conclusions.

TABLE III

CONVENTIONAL METHOD RESULT

\begin{tabular}{|c|c|c|c|c|c|c|c|c|c|}
\hline \multicolumn{7}{|c|}{$\boldsymbol{b x}$} & \multirow{2}{*}{$\boldsymbol{W} \boldsymbol{C}$} & $\sum(\boldsymbol{b} \boldsymbol{x})$ \\
\hline P1 & $\mathbf{P 2}$ & $\mathbf{P 4}$ & $\mathbf{P 5}$ & $\mathbf{P 9}$ & $\mathbf{P 1 2}$ & $\mathbf{P 1 3}$ & $\mathbf{P 1 4}$ & & \\
\hline 0 & 1 & 0 & 1 & 0 & 1 & 0 & 0 & 0.1188 & 0.36 \\
\hline
\end{tabular}

TABLE IV

CONVENTIONAL METHOd RESUlt For All DATa

\begin{tabular}{|c|c|c|c|c|c|c|c|c|c|c|}
\hline \multirow[b]{2}{*}{ Data } & \multicolumn{8}{|c|}{$b x$} & \multirow{2}{*}{$\sum W C$} & \multirow{2}{*}{$\sum b x$} \\
\hline & P1 & P2 & P4 & P5 & P9 & P12 & P13 & P14 & & \\
\hline 1 & 0 & 1 & 1 & 1 & 0 & 1 & 1 & 1 & 0.1188 & 0.72 \\
\hline 2 & 0 & 1 & 0 & 0 & 1 & 0 & 0 & 1 & 0.1188 & 0.36 \\
\hline & & & & & & & & & & \\
\hline 99 & 0 & 1 & 0 & 0 & 0 & 0 & 0 & 0 & 0.1188 & 0.12 \\
\hline 100 & 0 & 1 & 0 & 1 & 0 & 1 & 0 & 1 & 0.1188 & 0.48 \\
\hline
\end{tabular}

Finally, fuzzy MF is designed using a curve (triangulartrapezoidal) to represent each fuzzy parameter. The form of representation of the MF for each parameter in the fuzzy parameter group $a x$ is explained as follows: the parameter of the number of siblings (Figure 4), is divided into $2 \mathrm{LVs}$, namely; Low and High. The calculation of the fuzzy value manually is obtained through equations (1) and (2). The same way was performed technically for all fuzzy parameters: father's education, mother's education, family income, distance, journey time, social media, going, and GPA. Based on the case data in TABLE IV. The input value which is included in the parameter $(\mathrm{ax})$ is operated on the FL Sugeno method on the fuzzy process. The results of the fuzzy process in detail are shown in TABLE V.

$\mu_{\text {Low }(x)}=\left\{\begin{array}{cc}1 ; & x<1 \\ \frac{4-x}{4-1} ; & 1 \leq x<4 \\ 0 ; & x \geq 4\end{array}\right.$
$\mu_{\text {High }(x)}=\left\{\begin{array}{cc}0 ; & x<1 \\ \frac{x-1}{4-1} ; & 1 \leq x<4 \\ 1 ; & x \geq 4\end{array}\right.$

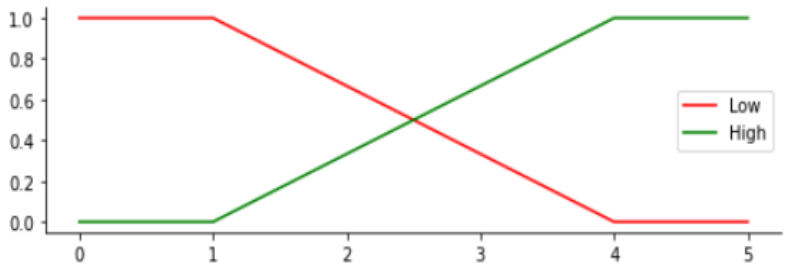

Figure 4. Membership Function Of Parameters Number Of Siblings

TABLE V

Result of Fuzzy Process

\begin{tabular}{|c|c|c|c|c|c|c|c|c|c|}
\hline P3 & P6 & P7 & P8 & P10 & P11 & & 15 & P16 & P17 \\
\hline 5 & 1 & 1 & 500000 & 5 & 20 & & 7 & 2 & 3.53 \\
\hline$\mu \mathrm{H}$ & $\mu \mathrm{L}$ & $\mu \mathrm{L}$ & $\mu \mathrm{L}$ & \begin{tabular}{l|l|}
$\mu \mathrm{L}$ & $\mu \mathrm{M}$
\end{tabular} & \begin{tabular}{l|l}
$\mu \mathrm{L}$ & $\mu \mathrm{M}$ \\
\end{tabular} & $\mu \mathrm{L}$ & $\mu \mathrm{H}$ & $\mu \mathrm{L}$ & $\mu \mathrm{E}$ \\
\hline 1.000 & 1.000 & 1.000 & 1.000 & \begin{tabular}{|l|l|}
0.833 & 0.167 \\
\end{tabular} & \begin{tabular}{|l|l|}
0.500 & 0.500 \\
\end{tabular} & 0.167 & 0.833 & 1.000 & 1.000 \\
\hline
\end{tabular}

Academically, fuzzy rules are defined to be applied in generating output values in the form of fuzzy set values from fuzzy input values. The fuzzy rule base is determined based on the value of the fuzzy process carried out in the inference process by using a collection and correlation between rules based on the MIN implication function. A total of 3,456 rule bases (1,728 for bad performance and 1,728 for good performance) are used in the model. This is based on the number of parameters ax and the number of linguistics in each parameter. The rules of fuzzy rules have ever mentioned in [7]. The fuzzy rules are then used in the next process, which is to perform a matrix process against the fuzzy rules that are used to find the minimum value of each rule and calculate the times value of the minimum value to the performance index (Bad has an index value of 50 and Good has an index value of 80). The results of the matrix process in detail are shown in TABLE VI.

TABLE VI

RULE MATRIX

\begin{tabular}{|c|c|c|c|c|c|c|}
\hline No & Rule & P3 & $\ldots$ & P17 & MIN & Index \\
\hline 1 & Rule 1732 & 1.00 & $\ldots$ & 1.00 & 1.00 & 80 \\
\hline 2 & Rule 1740 & 1.00 & $\ldots$ & 1.00 & 1.00 & 80 \\
\hline 3 & Rule 1748 & 1.00 & $\ldots$ & 1.00 & 1.00 & 80 \\
\hline 4 & Rule 1756 & 1.00 & $\ldots$ & 1.00 & 1.00 & 80 \\
\hline 5 & Rule 1780 & 1.00 & $\ldots$ & 1.00 & 1.00 & 80 \\
\hline 6 & Rule 1788 & 1.00 & $\ldots$ & 1.00 & 1.00 & 80 \\
\hline 7 & Rule 1796 & 1.00 & $\ldots$ & 1.00 & 1.00 & 80 \\
\hline 8 & Rule 1804 & 1.00 & $\ldots$ & 1.00 & 1.00 & 80 \\
\hline
\end{tabular}

The last step in the FL method procedure is the de-fuzzy process. The de-fuzzy process is used to interpret the fuzzy membership values into certain decisions or real numbers. This means returning the fuzzy value to a crisp value (real number), and changing the fuzzy output to a crisp value. 


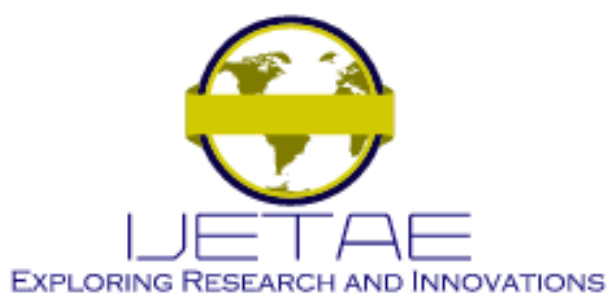

International Journal of Emerging Technology and Advanced Engineering

Website: www.ijetae.com (E-ISSN 2250-2459, Scopus Indexed, ISO 9001:2008 Certified Journal, Volume 11, Issue 10, October 2021)

The method used in this de-fuzzy process is the centroid method (center point) as in equation (3). This method pays attention to the condition of each fuzzy area, so as to produce more accurate results.

$$
Z=\frac{\sum_{i=1}^{n} a_{i} * z_{i}}{\sum_{i=1}^{n} a_{i}}
$$

The results of the de-fuzzy process produce a $\mathrm{Z}$ value of 80,000 . The final result of de-fuzzy ( $\mathrm{Z}$ ) is used to be multiplied by the total value of the fuzzy parameter weight to obtain the total value of the influence of the fuzzy parameter $\left(\sum(a x)\right)$. So that from the final process of the FL Sugeno method, the value $\left(\sum(a x)\right)$ of 70.49 will be obtained. The final calculation results on the FL Sugeno method can be seen in TABLE VII.

Table VII

Result Of Final Measurement From FL Sugeno Method

\begin{tabular}{|c|c|c|c|}
\hline Data & $\boldsymbol{Z}$ & $\sum(\boldsymbol{W F})$ & $\sum(\boldsymbol{a x})$ \\
\hline 1 & 80.00 & 0.881 & 70.49 \\
\hline 2 & 50.00 & 0.881 & 44.06 \\
\hline$\ldots$ & $\ldots$ & $\ldots$ & $\ldots$ \\
\hline 99 & 80.00 & 0.881 & 70.49 \\
\hline 100 & 80.00 & 0.881 & 70.49 \\
\hline
\end{tabular}

Table VIII

Result of Decision Value (DV)

\begin{tabular}{|c|c|c|c|}
\hline Dataset & $\sum(\boldsymbol{a x})$ & $\sum(\boldsymbol{b x})$ & $\boldsymbol{D V}$ \\
\hline 1 & 70.49 & 0.71 & 71.20 \\
\hline 2 & 44.06 & 0.36 & 44.41 \\
\hline$\ldots$ & $\ldots$ & $\ldots$ & $\ldots$ \\
\hline 99 & 70.49 & 0.12 & 70.61 \\
\hline 100 & 70.49 & 0.48 & 70.96 \\
\hline
\end{tabular}

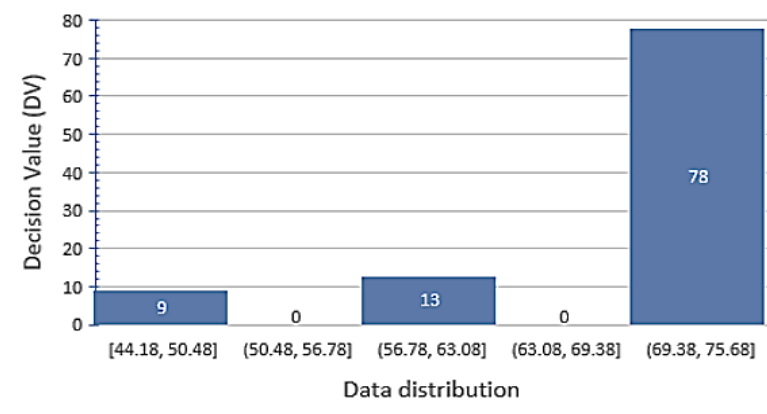

Figure 5. Data Distribution of AP Measurement

The final stage of AP assessment based on the DSM-AP model is carried out. AP assessment in the form of DV is generated through a calculation process against the calculation results of both FL Sugeno (ax) and conventional (bx) methods. The calculation details are shown as DV=70.49+ 0.36=70.85.
From the results of the case input in Table 4.5 which is calculated based on the DSM-AP model, the results of the AP assessment (DV) of 70.85 are obtained from the range of values from 0 to 100 . The value of 70.85 means that the performance results get a value of 70.85 as a result Performance appraisal is obtained by considering 17 parameters as subjective values that can affect the results of academic performance appraisal decisions that strengthen than the standard GPA assessment by involving various parameters to be considered. The data from the final calculation of the model in producing DV is shown in TABLE VIII.

From the final calculation results of the AP assessment, a distribution of data from the AP assessment is generated. The results of the data distribution are shown in Figure 5. Meanwhile, for each parameter, the influence value was obtained from the research conducted based on the weight values in TABLE IX. The influence value of the parameters is depicted through the graph in Figure 5 The weight value for the influence of each parameter is ordered from the largest weight value (GPA) to the smallest (place of residence).

\section{H. Model Verification}

The model verification test aims to check the degree of truth of the model that has been successfully built to deal with a problem based on the concept of the theory used [11]. Model verification is made to prove the truth of a model by checking the formula, calculation, procedure used with reference (theory). The verification test in this study was carried out on four elements consisting of the variables used, the suitability of the calculation procedure, the suitability of the formula and the suitability of the calculation results.

Comparison of the results of data processing for AP assessment using the DSM-AP model built with PHP 7.4 programming compared to using conventional-based mathematical calculations using MS Excel, the comparison results are shown in TABLE IX.

TABLE IX

VERIFICATION FOR AP MEASUREMENT

\begin{tabular}{|c|c|c|c|c|c|c|c|}
\hline \multirow{2}{*}{ Data } & \multicolumn{3}{|c|}{ AP Measured by DSM-AP } & \multirow{2}{*}{ Data } & \multicolumn{3}{|c|}{ AP Measured Manually } \\
\hline & $a x$ & $b x$ & $D V$ & & $\sum(\boldsymbol{a x})$ & $\sum(\boldsymbol{b x})$ & $D V$ \\
\hline 1 & 70.49 & 0.72 & 71.20 & 1 & 70.49 & 0.72 & 71.20 \\
\hline 2 & 44.06 & 0.36 & 44.42 & 2 & 44.06 & 0.36 & 44.42 \\
\hline & & & & & & & \\
\hline 99 & 70.49 & 0.12 & 70.61 & 99 & 70.49 & 0.12 & 70.61 \\
\hline 100 & 70.49 & 0.48 & 70.97 & 100 & 70.49 & 0.48 & 70.97 \\
\hline
\end{tabular}




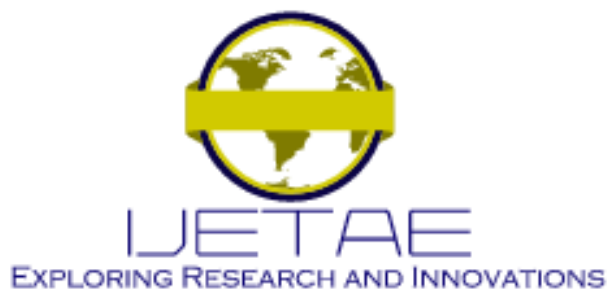

International Journal of Emerging Technology and Advanced Engineering

Website: www.ijetae.com (E-ISSN 2250-2459, Scopus Indexed, ISO 9001:2008 Certified Journal, Volume 11, Issue 10, October 2021)

TABLE X

VERIFICATION RESULT OF DSM-AP

\begin{tabular}{|c|c|c|c|c|}
\hline Sub-Model & Element & Model & References & Verification Value \\
\hline \multirow{4}{*}{ Fuzzy Logic (ax) } & $\Sigma$ Variable & 2 & 2 & \multirow{12}{*}{1.00} \\
\hline & Procedure & $\mathrm{V}$ & $\mathrm{V}$ & \\
\hline & Formula & $\checkmark$ & $\checkmark$ & \\
\hline & Result & $44,060-70,490$ & $44,060-70,490$ & \\
\hline \multirow{4}{*}{ Conventional (bx) } & $\Sigma$ Variable & 9 & 9 & \\
\hline & Procedure & $\checkmark$ & $\checkmark$ & \\
\hline & Formula & $\checkmark$ & $\checkmark$ & \\
\hline & Result & $0.120-0.720$ & $0.120-0.720$ & \\
\hline \multirow{4}{*}{ Math Model (DV) } & $\Sigma$ Variable & 2 & 2 & \\
\hline & Procedure & $\checkmark$ & $\checkmark$ & \\
\hline & Formula & $\checkmark$ & $\checkmark$ & \\
\hline & Result & $44,180-7,849$ & $44,180-7,849$ & \\
\hline
\end{tabular}

Meanwhile, the model verification test was applied to three (3) sub-model blocks, namely the FL Sugeno ( $a x)$, conventional $(b x)$, and the Mathematic model. Verification test is carried out on four verification elements; 1) the variable element tests the suitability between the number of variables in the formula used for each sub model block of the model against the reference, 2) the procedure / function element tests the suitability for each procedure that is executed on each sub model block of the model against the reference, 3 ) the formula element test the suitability of the formula used for each sub-model block of the model against the reference, 4) the calculated elements test the suitability of the calculation results generated for each submodel block of the model against the reference. The conformity form of the test results is symbolized by " $\checkmark$ " in the conformity column. The deviation value states the difference from the verification test results from all elements of each sub-model block of the model to the reference with the standard deviation value below 0.05 . The results of the verification test with a true value will be symbolized by a value of 1 and 0 indicating a discrepancy from the results of the verification test carried out. The results of the model verification test are shown in TABLE $X$.
Based on TABLE $X$, the verification results can be concluded that the largest verification value is 1.0 ; with detailed explanation for the variable verification value of 1.0; the verification procedure value is 1.0; the formula verification value is 1.0 ; and the calculated value is also 1.0. From the verification calculation table data, the overall deviation value is less than 0.05 , so it can be said that the DSM-AP model is well developed.

\section{Model Validation}

Model validation is the degree of truth of the data values used to be compared with data in the field [11]. Model validation is closely related to the variables and data values used in building the model. By using model validation, it can be proven whether the variables and data have the correct values according to the calculations in the field. The assessment of the DSM-AP model validation data is shown in the table. The results of the assessment of the model data validation test are shown in TABLE XI (with one examples).

In TABLE XI, in evaluating the model validation, the table shown is a list of parameters used in building the DSM-AP model. The results of the data are compared with the process whose data is taken according to what is in the field. There are 17 validated data, where the data are student personal data and student academic scores used in the AP assessment. The results of the validation test are summarized in TABLE XII. 


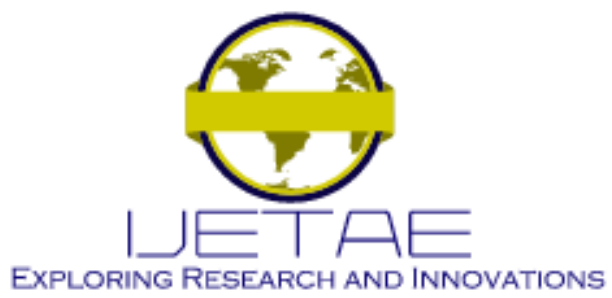

International Journal of Emerging Technology and Advanced Engineering

Website: www.ijetae.com (E-ISSN 2250-2459, Scopus Indexed, ISO 9001:2008 Certified Journal, Volume 11, Issue 10, October 2021)

TABLE XI

VALIDATION MEASUREMENT FOR DSM-AP

\begin{tabular}{|c|c|c|c|c|c|c|c|c|c|c|}
\hline \multirow{2}{*}{ Sub Model } & \multirow{2}{*}{$\begin{array}{c}\text { Parameter } \\
\text { (Data) }\end{array}$} & \multirow{2}{*}{ Model } & \multirow{2}{*}{ Field } & \multicolumn{2}{|c|}{ Variable } & \multicolumn{2}{|c|}{ Value } & \multicolumn{3}{|c|}{ Test Result } \\
\hline & & & & $\mathbf{T}$ & $\mathbf{F}$ & $\mathbf{T}$ & $\mathbf{F}$ & FP & TN & FN \\
\hline \multirow[b]{3}{*}{ DSM-AP } & Sex & $\begin{array}{l}\text { Man, } \\
\text { Woman }\end{array}$ & $\begin{array}{l}\text { Man, } \\
\text { Woman }\end{array}$ & 1 & & 1 & & 1 & & \\
\hline & $\ldots$ & & & & & & & & & \\
\hline & $\begin{array}{l}\text { GPA } \\
\text { 1. Poor } \\
\text { 2. Good } \\
\text { 3. Very Good } \\
\text { 4. Excellent }\end{array}$ & $\begin{array}{l}0.00-2.50 \\
2.51-2.99 \\
3.00-3.59 \\
3.60-4.00\end{array}$ & $\begin{array}{l}0.00-2.50 \\
2.51-2.99 \\
3.00-3.59 \\
3.60-4.00\end{array}$ & $\begin{array}{l}1 \\
1 \\
1 \\
1\end{array}$ & & $\begin{array}{l}1 \\
1 \\
1 \\
1\end{array}$ & & $\begin{array}{l}1 \\
1 \\
1 \\
1\end{array}$ & & \\
\hline Total & & & & 32 & & 32 & & 32 & & \\
\hline
\end{tabular}

TABLE XII

SUMMARY OF VALIDATION MEASUREMENT

\begin{tabular}{|c|c|c|c|l|}
\hline \multicolumn{2}{|c|}{} & \multicolumn{2}{|c|}{ Value } & \multirow{2}{*}{} \\
\cline { 3 - 4 } \multicolumn{2}{|c|}{} & $\mathrm{T}$ & $\mathrm{F}$ & \\
\hline \multirow{3}{*}{ Validation } & $\mathrm{T}$ & $\mathrm{TP}=32$ & $\mathrm{FN}=0$ & Sensitivity $=1.00$ \\
\cline { 2 - 4 } & $\mathrm{F}$ & $\mathrm{FP}=0$ & $\mathrm{TP}=0$ & Specify $=0.00$ \\
\hline & & $\mathrm{NPP}=1.00$ & $\mathrm{NPN}=0.00$ & \\
\hline
\end{tabular}

Based on TABLE XII, it can be seen that the sensitivity value of the model is 1.00 , which means that the model has $100 \%$ correct parameter values and nothing wrong. The NPP value of 1.00 indicates that the model has $100 \%$ correct parameters. None of the variables are wrong, so the data generated by the model is in accordance with the calculation results when compared to using existing parameters in the field.

\section{CONCLUSION AND FURTHER WORKS}

Based on the research that has been done, the following conclusions are obtained. The first, in completing and supporting the research objectives, the AP assessment model is developed in the form of DSM, the model is built using the FL, conventional, and mathematical methods, the selection of methods in building the model is carried out by adjusting the research needs and in an effort to solve the problems contained in the FTTE related to the AP assessment, a new model was successfully built which was named the DSM-AP model. Furthermore, the DSM-AP model is used in research related to AP research. The model was built by involving as many as 17 parameters including gender, area of origin, number of siblings, family status, father's education, mother's education, family income, motivation, mileage, travel time, type of transportation, organizational scholarship, social media, traveling, and GPA.
Parameters go through several configuration processes to be used in the model including grouping and weighting configurations. The last one said that the various parameters involved in the research indicate that they have various influences on the final decision results of the DSMAP model. Parameters are grouped into parameters $a x$ and $b x$, where the $a x$ parameter appears to have a more significant effect on producing the final decision result of 0.88111 or $88 \%$, while the $b x$ parameter only plays a small role in influencing the final decision result of 0.11889 or $12 \%$. Also, mentioned that the verification and validation value of model were done with

The suggestions that can be submitted to get better AP assessment results in further research include: 1) Further research can be carried out using the clustering method in the assessment process with the coverage of the previously submitted data. The non-hierarchical clustering algorithm based on fuzzy, namely, Fuzzy C-Means, Fuzzy C-Means is one of the techniques for determining the optimal cluster in vector space based on the Euclidian normal form for the distance between vectors. The application of Fuzzy CMeans is useful in fuzzy modeling, especially in identifying fuzzy rules. The use of the Fuzzy C-Means method is very possible to be carried out in research related to AP assessment. 2) Adding the scope of research in terms of the number of student data and new parameters that make it possible to get the results of the AP assessment in a new form by providing information in the form of knowledge of the parameters involved in the AP assessment. So that the form of knowledge from the assessment will be more varied which can be given to universities and become a reference in determining strategies to improve the quality of student performance effectively. 


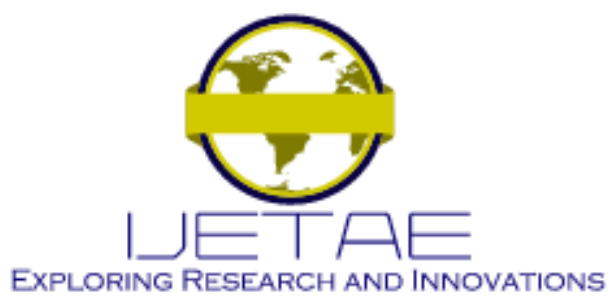

International Journal of Emerging Technology and Advanced Engineering

Website: www.ijetae.com (E-ISSN 2250-2459, Scopus Indexed, ISO 9001:2008 Certified Journal, Volume 11, Issue 10, October 2021)

\section{REFERENCES}

[1] Abledu, G. K. 2012. Multiple Regression Analysis of Assessment of Academic Performance of Students in the Ghanaian Polytechnics. The International Institute for Science, Technology and Education (IISTE), 2(9), 15-25.

[2] Estrera, P., Natan, P., Rivera, B., and Colarte, F. 2017. Student Performance Analysis for Academic Ranking Using Decision Tree Approach in University of Science and Technology of Southern Philippines Senior High School. International Journal of Engineering and Techniques, 3(5), 147-154.

[3] Petroudi, S. H., Pirouz, M., and Pirouz, B. 2013. Application of Fuzzy Logic for Performance Evaluation of Academic Students. 2013 13th Iranian Conference on Fuzzy Systems (IFSC), Qazvin, Iran: IEEE, 1-5.

[4] Yadav, R. S., Soni, A. K., and Pal, S. 2014. A Study of Academic Performance Evaluation Using Fuzzy Logic Techniques. 2014 International Conference on Computing for Sustainable Global Development (INDIACom), New Delhi, India: IEEE, 48-53.

[5] Çebi, A., and Karal, H. 2017. An Application of Fuzzy Analytic Hierarchy Process (FAHP) for Evaluating Students' Project. Educational Research and Reviews (ERR), 12(3), 120-132.

[6] Feng, Q., Yao, C., and Xiao, Z. 2018. Construction of Students' Comprehensive Quality Evaluation Model Based on Improved AHP. 2018 13th International Conference on Computer Science \& Education (ICCSE), Colombo: IEEE, 1-5.

[7] Kurniawan, D., and Utama, D. N. 2021. Decision Support Model using FIM Sugeno for Assessing the Academic Performance. Advances in Science, Technology and Engineering Systems Journal, 6(1), 605-611.

[8] Narad, A., and Abdullah, B. 2016. Academic Performance of Senior Secondary School Students: Influence of Parental Encouragement and School Environment. (M. K. Mihir, Ed.) Rupkatha Journal on Interdisciplinary Studies in Humanities, 8(2), 12-19.

[9] Sprague, R. 1980. A Framework for the Development of Decision Support Systems. JSTOR, 4(4), 1-26.

[10] Utama, D. N. 2021. Logika Fuzzy untuk Model Penunjang Keputusan, Dilengkapi dengan Penerapan Contoh Kasus. Yogyakarta: Penerbit Garudhawaca.
[11] Utama, D. N., Lazuardi, L. I., Qadrya, H. A., Caroline, B. M., Renanda, T., and Sari, A. P. 2017. Worth eat: An Intelligent Application for Restaurant Recommendation based on Customer Preference (Case Study: Five Types of Retaurant in Tangerang Selatan Region, Indonesia). International Conference on Information and Communication Technology, 1-4.

[12] Setyono, A., and Aeni, S. N. 2018. Development of Decision Support System for Ordering Goods using Fuzzy Tsukamoto. International Journal of Electrical and Computer Engineering (IJECE), 8(2), 1182-1193.

[13] Fakhry, H. 2010. A Fuzzy Logic Based Decision Support System for Business Situation Assessment and e-Business Models Selection. Communications of the IIMA, 10(4), 61-76.

[14] Zadeh, L. 1978. Fuzzy sets as a basis for a theory of possibility. Fuzzy Sets and Systems, 1(1), 3-28.

[15] Salvi, A. H., Khairnar, M. M., Shaikh, S. R., and Kokani, S. T. 2018 Prediction and Evaluation of Students Academic Performance using Fuzzy Logic. International Research Journal of Engineering and Technology (IRJET), 5(2), 1797-1799.

[16] Deniz, D., and Ersan, I. 2002. An Academic Decision Support System Based on Academic Performance Evaluation for Student and Program Assessment. Computer Science, 18(2), 236-244.

[17] Mueen, A., Zafar, B., and Manzoor, U. 2016. Modeling and Predicting Students' Academic Performance Using Data Mining Techniques. International Journal Modern Education and Computer Science, 8(11), 36-42.

[18] Jamuna, M., and Shoba, S. A. 2017. Educational data mining and students performance prediction using SVM techniques. International Research Journal of Engineering and Technology (IRJET), 4(8), 1248-1254.

[19] Salal, Y. K., Abdullaev, S., and Kumar, M. 2019. Educational Data Mining: Student Performance Prediction in Academic. International Journal of Engineering and Advanced Technology (IJEAT), 8(4C), 54-59.

[20] Kumar, A. D., Pandi, R. S., and Palanisamy, V. 2019. Prediction of Student Performance using Hybrid Classification. International Journal of Recent Technology and Engineering (IJRTE), 8(4), 65666670.

[21] Cavallaro, F. 2015. A Takagi-Sugeno Fuzzy Inference System for Developing a Sustainability Index of Biomass. (M. Rosen, Ed.) Sustainability, 7(9), 12359-12371. 